\title{
The Effect of the Public Health Nursing Course on Students' Healthy Lifestyle Behaviors
}

\author{
Ayse Dost ${ }^{1}$, Sura Kaya ${ }^{2}$, Nihal Sunal ${ }^{3}$ \\ ${ }^{1}$ Istanbul Medipol University, Health Sciences Faculty, Nursing Department, Istanbul, Turkey. \\ ${ }^{2}$ Nursing Department; Health Sciences Faculty, Istanbul Medipol University, Istanbul, Turkey. \\ ${ }^{3}$ Nursing Department; Health Sciences Faculty, Istanbul Medipol University, Istanbul, Turkey. \\ Correspondence Author: Ayse Dost \\ E-mail: adost@medipol.edu.tr
}

Received: $04.07 .2020 \quad$ Accepted: 03.11 .2021

\begin{abstract}
Objective: This study was conducted to examine the effect of the public health nursing course given to nursing students on their healthy lifestyle behaviors.

Methods: A one-group pretest-posttest quasi-experimental design was used in the study, which was carried out with 80 students studying at the nursing department of a foundation university and volunteering to participate in the study. The data were collected twice before and after the course using the Personal Information Form and the Health-Promoting Lifestyle Profile (HPLP). Descriptive statistics, Mann-Whitney U and Kruskal-Wallis tests, the paired t-test, were used to evaluate the data.

Results: After the public health nursing course, a significant increase was determined in the students' HPLP total score and the "exercise", "nutrition", "self-realization", "health responsibility", "stress management", and "interpersonal support" subscale scores ( $p<0.05)$. A significant difference was found in the "HPLP" scale total scores according to the students' physical activity level variable, "interpersonal support" subscale according to the gender and body mass index variables, in the "exercise" subscale according to the smoking status and physical activity level variable $(p<0.05)$.

Conclusion: The public health nursing course was observed to affect nursing students' healthy lifestyle behaviors. For a healthy lifestyle of nursing students, it is recommended that programs for gaining these behaviors be developed in light of the current literature and advanced studies should be carried out to determine the transformation status of the provided education into behavior.
\end{abstract}

Keywords: Healthy lifestyle behaviors, public health nursing, nursing students

\section{INTRODUCTION}

Chronic diseases, which are a significant public health problem, are affected by lifestyle choices. Healthy lifestyle behaviors such as healthy nutrition, exercise, regular and adequate sleep, and avoiding excessive alcohol consumption help prevent and control chronic diseases (1). Nurses, who take an essential place in providing healthcare and education to individuals, are the key in promoting healthy lifestyle behaviors in society. The nurse, who expects behavior change from an individual, must primarily lead the individual and be a role model by exhibiting the same behavior (2). Personal health practices of healthcare professionals affect the health education and guidance they provide to patients (3). A study found that among nurses providing health education to society, those with a normal body mass index (BMI) created more confidence in individuals (4). Furthermore, it is known that developing and adopting preventive health behaviors from an early age increase compliance with behavior. Since changing lifestyle behaviors becomes more difficult with the increasing age, it is essential to encourage healthy behaviors at the beginning of nursing education (5). Moreover, the university period is among the risky periods for gaining risky behaviors such as unhealthy nutrition, sedentary lifestyle, smoking, alcohol or substance use, unprotected sexual intercourse, self-harming behaviors, risky (drunk, fast, unbelted, unlicensed) driving, skipping school, dropping out of school, and indifference to lessons (6). In the literature, it is recommended that courses for nursing students to gain these behaviors should be included in the curriculum for them to have a healthy lifestyle (7-9). Group training is the most common intervention to improve students' healthy lifestyle behaviors. Studies examining the effect of shortterm group education programs on improving the health of 
university students have shown that students improve their healthy lifestyle behaviors, increase their physical activity (PA) levels, increase the consumption of vegetables and fruits, and the program causes weight loss and changes in body composition (10-15). Moreover, there are subjects related to health behaviors in courses such as public health nursing and health promotion in nursing undergraduate education. There are many descriptive studies on the health behaviors of students in Turkey. However, studies explaining the effect of courses involving healthy lifestyle behaviors on students' behaviors are limited.

The hypothesis to be tested in the study is as follows:

- 'The public health nursing course affects students' healthy lifestyle behaviors".

\section{METHODS}

\subsection{Study Design}

This study was conducted using a one-group pretest-posttest quasi-experimental design to examine the effect of the public health nursing course given to nursing students on their healthy lifestyle behaviors.

\subsection{Research Participants}

The study was carried out with 80 students who were enrolled in the third year of the nursing department of a foundation university and who took the public health nursing course in the spring term of the 2018-2019 academic year. Eighty students who responded to the data collection tools completely were included in the study using the full counting sampling method.

\subsection{Data Collection Tools}

The study data were collected using the "Personal Information Form" and the "Health-Promoting Lifestyle Profile (HPLP)."

Personal Information Form: It is a form prepared in line with the literature and consisting of seven questions about age, gender, marital status, weight, BMI, smoking, and PA level.

Health-Promoting Lifestyle Profile (HPLP): It is a 4-point Likert-type scale, the validity and reliability studies of which were conducted by Esin (1999) and which measures health promotion behaviors with six subscales "self-realization, health responsibility, exercise, nutrition, interpersonal support, and stress management" and 48 items. The lowest score that can be obtained from the scale is 48 , and the highest score is 192 . There are no negative items on the scale (16). Cronbach's alpha $(\alpha)$ coefficient of the scale is 0.91 , and it was calculated to be 0.87 in this study. The high reliability limit was above 0.80 , and the measurement results were reliable (17).

\subsection{Intervention}

The public health nursing course is taught as a 4-hour theoretical course for 14 weeks in the spring semester of the third-year curriculum of the nursing department. Subjects such as "the definition of health, preventive health services, the concept of health promotion, healthy nutrition for the prevention of chronic health problems, exercise, stress management, smoking and alcohol use and immunization for the prevention of infectious diseases, personal hygiene and cleaning, safe sex life" are included in the content of the course to ensure that students gain healthy lifestyle behaviors. The researchers provided education to students through direct instruction, question-answer, discussion, and video watching methods. Moreover, the Healthy Lifestyle Behaviors Booklet prepared by the researchers was given to students at the beginning of the course. The students did not take any other course to develop healthy lifestyle behaviors before the public health nursing course in the nursing undergraduate program.

\subsection{Data Collection}

The data were collected by the researchers using the faceto-face interview method before the beginning of the public health nursing course and at the end of the 14-week course period. After explanations about the study were made, the students were asked to find a nickname for themselves and write their nicknames instead of the name and surname in the data collection tools. The students filled out the data collection tools in approximately 15-20 minutes. At the end of the course period, the students filled out the data collection tools again using the same nicknames.

\subsection{Ethical Considerations}

The written consent was obtained from the ethics committee of a foundation university (10840098-604.01.01-E.98), and the necessary written permission was obtained from the relevant institution before starting the study. The students participating in the study were asked to write a nickname instead of their name and surname, and the data were anonymized. Verbal and written consent was obtained from the students who agreed to participate in the study voluntarily after the study data were announced not to be used elsewhere other than the research report.

\subsection{Data Analysis}

The data were analyzed in the computer environment, and descriptive statistical methods of number, percentage, mean and standard deviation were used. The pretestposttest comparison of the scale and subscale mean scores was made using the paired t-test for dependent samples. The distribution of numerical variables was tested using the Kolmogorov-Smirnov test, and it was identified that the data were not normally distributed $(p<0.05)$. Therefore, the differences between individual characteristic variables and 
the questionnaire scores were analyzed using the MannWhitney $U$ and Kruskal-Wallis tests. The statistical significance was considered as $p<0.05$.

\section{RESULTS}

The mean age of the students in the study was $21.60 \pm 1.19$ years, and $87.5 \%$ of the students were female, and $97.5 \%$ were single. Of the students, $12.5 \%$ smoked. The mean weight was $56.99 \pm 11.81$, the mean $\mathrm{BMI}$ was $21.22 \pm 3.10$, and when BMI was evaluated, $12.5 \%$ were observed to be overweight. Of the students, 35\% stated that they had insufficient PA, $57.5 \%$ stated that they did "moderate to vigorous PA for at least 20 minutes" 1 day a week, and $7.5 \%$ stated that they did "moderate to vigorous PA for at least 20 minutes" 1-2 times a week (Table 1).

A statistically significant difference was revealed between the pretest and posttest HPLP and subscale scores of the students participating in the study $(\mathrm{p}<0.05)$. It was determined that the posttest scores of the HPLP and its subscales were significantly higher than the pretest scores (Table 2).

Table 1. Characteristics of nursing students $(n=80)$

\begin{tabular}{|c|c|c|}
\hline Characteristics & Mean & SD \\
\hline Age (years) & 21.60 & 1.19 \\
\hline Weight (kg) & 56.99 & 11.81 \\
\hline \multirow[t]{2}{*}{ BMI $\left(\mathrm{kg} / \mathrm{m}^{2}\right)$} & 21.22 & 3.10 \\
\hline & $\mathrm{n}$ & $\%$ \\
\hline \multicolumn{3}{|l|}{ Sex } \\
\hline Female & 70 & 87.5 \\
\hline Male & 10 & 12.5 \\
\hline \multicolumn{3}{|l|}{ Marital status } \\
\hline Married & 2 & 2.5 \\
\hline Single & 78 & 97.5 \\
\hline \multicolumn{3}{|l|}{ Smoking Status } \\
\hline Smoker & 70 & 87.5 \\
\hline Non-smoker & 10 & 12.5 \\
\hline \multicolumn{3}{|l|}{ BMI Classification } \\
\hline Normal & 70 & 87.5 \\
\hline Overweight & 10 & 12.5 \\
\hline \multicolumn{3}{|l|}{ PA Level } \\
\hline Insufficient PA & 28 & 35 \\
\hline $\begin{array}{l}\text { At least } 20 \mathrm{~min} \text { of moderate to } \\
\text { vigorous PA } 1 \text { day/week }\end{array}$ & 46 & 57.5 \\
\hline $\begin{array}{l}\text { At least } 20 \text { min of moderate to } \\
\text { vigorous PA 1-2 times/week }\end{array}$ & 6 & 7.5 \\
\hline
\end{tabular}

$B M I=$ body mass index; $P A=$ physical activity.
The pretest and posttest comparisons of the HPLP and subscale scores according to the students' descriptive characteristics are given in Table 3. The interpersonal support subscale posttest score of female students was positively higher than that of male students, and the difference was significant $(Z=-2.109, p=0.035)$. The interpersonal support subscale posttest score of students with normal weight was higher than that of overweight students, and the difference was significant $(\mathrm{Z}=-2.251, \mathrm{p}=0.024)$. The exercise subscale posttest score of non-smokers was found to be higher than that of smokers, and the difference was significant $(Z=-2.204$, $p=0.028$ ). The exercise subscale pretest and posttest scores of the students who did "at least 20 min of moderate to vigorous PA 1-2 times/week" were found to be higher than other students, and the difference was significant $(p<0.05)$. The HPLP posttest score of the students who did "at least 20 min of moderate to vigorous PA 1-2 times/week" was found to be higher than other students, and the difference was significant (KW=7.397, $\mathrm{p}=0.025)$.

Table 2. Pre-and post-assessment of the HPLP scores $(n=80)$

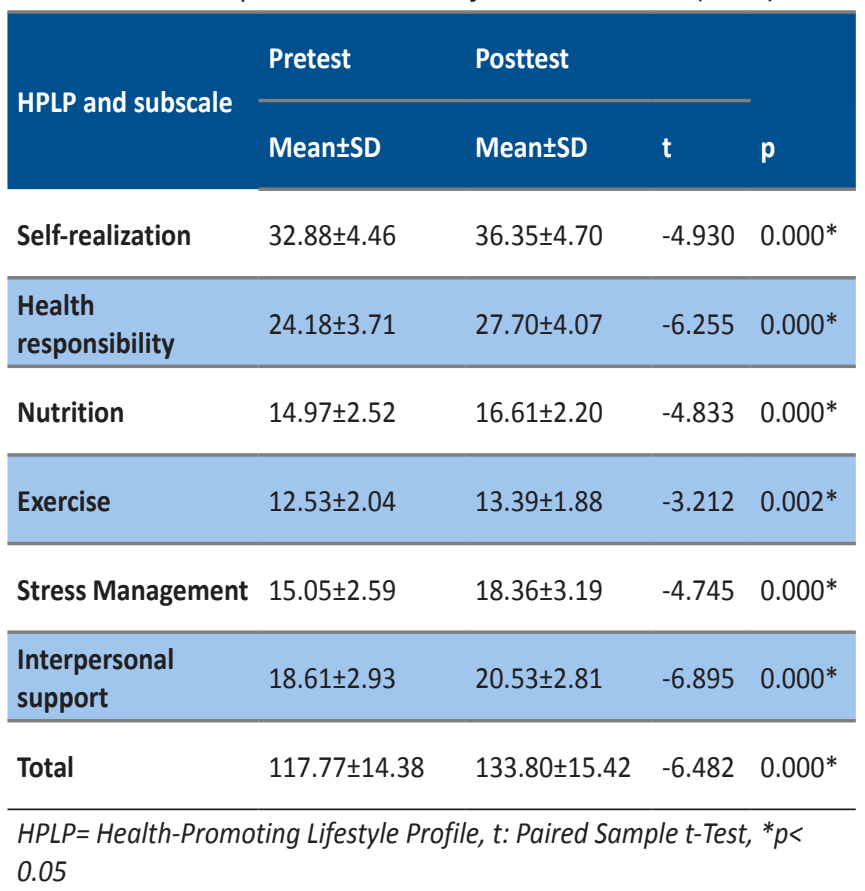


Table 3. Comparison of the HPLP and subscale scores according to the students' characteristics ( $n=80)$

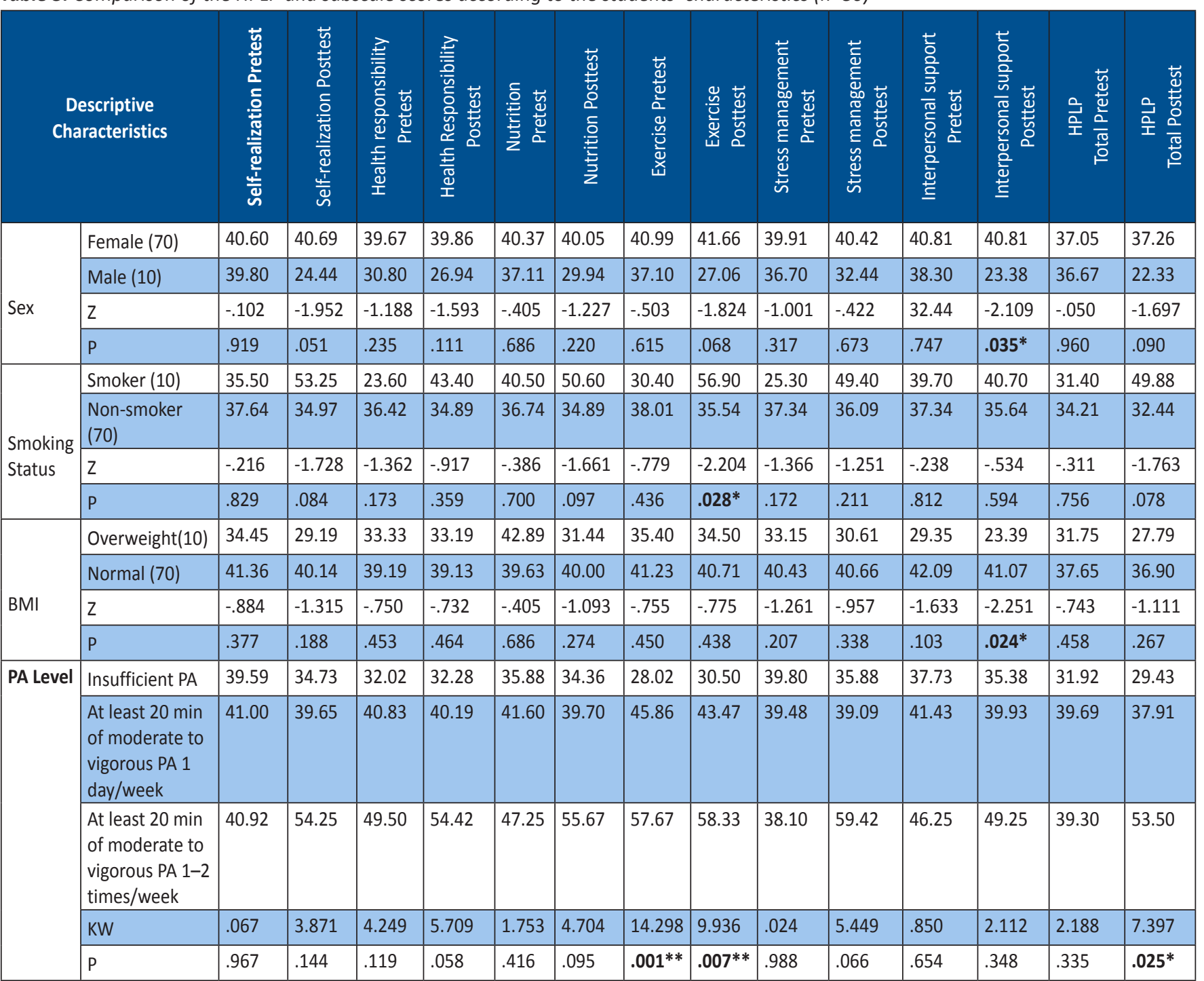

HPLP= Health-Promoting Lifestyle Profile, BMI= body mass index, PA= physical activity, Z= Mann-Whitney U test, KW=Kruskal-Wallis test, ${ }^{*} p<.05, * * p<.01$

\section{DISCUSSION}

Although it is thought that nurses and other healthcare professionals may have better lifestyle behaviors than society, this is not always true. Some studies indicate that the health status of nurses and other healthcare professionals may actually be lower than that of the general population (18). The current studies identify nursing students to be at risk for unhealthy lifestyle behaviors and mental health problems. Moreover, while there are many descriptive studies on the healthy lifestyle behaviors of nursing students, there are very few interventional studies on improving the health of these students (19). Therefore, it is necessary to organize training programs to improve the health of nursing students. In this study, the effect of the public health nursing course on healthy lifestyle behaviors was examined with the HPLP (all points and subscales). After the public health nursing course, there was an increase in the HPLP and all subscales.
Thus, it was determined that the public health nursing course affected healthy lifestyle behaviors.

Subjects such as the concept of health, preventive health services, health promotion, healthy nutrition for preventing chronic health problems, exercise, stress management, smoking and alcohol use behaviors, immunization for preventing infectious diseases, personal hygiene and cleaning, and safe sex life were included in the content of the public health nursing course to ensure that healthy lifestyle behaviors were gained. It is thought that the inclusion of these subjects contributes to the increase in students' HPLP and subscale scores. Similarly to the current research findings, Coskun et al. (2019) and Alpar et al. (2008) found that the HPLP scores increased statistically significantly after the training provided to nursing students $(3,7)$. In a study conducted in Taiwan by Hsiao et al. (2005), an increase was observed in students' HPLP scores after the health promotion course given to nursing students (18). In a study conducted 
by Yeh et al. (2005) with 42 nursing students taking the public health nursing course, a significant increase was observed in students' healthy nutrition and PA at the end of the course compared to the period before the course (20).

A study carried out by Melynk et al. (2014) to evaluate the effect of the 15-week Healthy Lifestyle Behaviors course given to 36 university students on their healthy lifestyle choices, PA, cognitive beliefs, knowledge, and mental health found that students were more willing to apply healthy lifestyle behaviors and their physical activities increased significantly compared to the baseline (12). Contrary to the research findings, the 8-week health promotion and enhancement program, prepared by Erenoglu et al. (2019) for university students and including the subjects of balanced nutrition, stress management, effective communication, health responsibility, and spiritual development, was observed to affect healthy lifestyle behaviors (21).

In this study, the posttest interpersonal support subscale scores of female students and group of students with normal weight were higher. Likewise, Gill et al. (2017) reported that the perceived family support of female students was higher than that of male students (22). Social support refers to the functions of emotional, informational, and instrumental assistance from family, friends, teachers, and significant others. Thus, social support is an umbrella term that includes various supports from all relationships that are significant for the individual (23). Previous studies have shown that women are more likely than men to report more social support and be more socially involved in well-being $(24,25)$. Gender has always been an important factor in these studies on interpersonel support, and there have been results reporting that females receive more interpersonal support from their environment and perceive this social support better.

Similar to our study findings, Göger et al. (2019) and Yılmazel (2016) also determined that the interpersonal support subscale score values of females with normal weight were higher than those of obese women $(26,27)$. In the study carried out by Kocaman and Telatar (2020), it was stated that overweight individuals were under social pressure from family, spouses, and friends to lose weight (28). It can be said that the low interpersonal support score of overweight individuals is due to the effect of social pressure on them. There are positive correlations between social relationships and well-being. Diener and Ryan (2009) reported that "individuals with numerous friends and family members were likely to have higher subjective well-being" (29).

The exercise subscale posttest score of non-smoking students was higher than that of smoking students. A negative and significant relationship was found between physical exercise and smoking in many studies (30). Previous studies have found a significant relationship between physical exercise performance and lung function capacity (31-33). The most important factor explaining this relationship is that smoking significantly affects lung functions and consequently affects physical exercise performance.
The HPLP posttest score, exercise subscale pretest and posttest score of the students who stated that they did "at least 20 minutes of moderate to vigorous PA 1-2 times a week" were found to be higher than the other students. PA is defined as "activities that occur with energy consumption using our muscles and joints in daily life, increase heart and respiratory rate and result in fatigue at different intensities." The activities we define as physical activity can be activities that we choose for entertainment purposes, or they can be activities done out of necessity or necessity (such as housework). On the other hand, exercise is "a subcategory of PA, is planned, structured, repetitive, and purposeful" (34). Therefore, a person who does "moderate to vigorous PA" for at least 20 minutes 1-2 times a week means exercising. This supports the present finding.

\section{CONCLUSION}

In this study, a contribution was made to developing healthy lifestyle behaviors by applying a classroom-based education program for nursing students. The HPLP and subscale scores of students increased statistically significantly after the public health nursing course. The target behavioral interventions involving health and life skills should be compulsorily provided to nursing students to ensure the health of future healthcare professionals. At the same time, it can be said that the education received by nursing students will affect the health services they will provide to society in the future and that today's students will be an important role model for the healthy society of tomorrow. For a healthy lifestyle of nursing students, it is recommended that programs for gaining these behaviors should be developed in light of the current literature and advanced studies should be carried out to determine the transformation status of the provided education into behavior.

\section{Acknowledgments}

We sincerely thank all of the students for their participation, which made this work possible.

\section{Conflict of interest}

The authors declare that they have no conflict of interest.

\section{REFERENCES}

[1] Centers for Disease Control and Prevention. How you can prevent chronic diseases. National Center for Chronic Disease Prevention and Health Promotion (NCCDPHP): 2019.

[2] International Council of Nurses. Delivering quality, serving communities: nurses leading chronic care. International Council of Nurses, 3, place Jean-Marteau, 1201 Geneva, Switzerland: 2010.

[3] Ecevit Alpar S, Senturan L, Karabacak U, Sabuncu N. Change in the health promoting lifestyle behaviour of Turkish university nursing students from beginning to end of nurse training. Nurse Educ Pract 2008; 8(6): 382-388. 
[4] Hicks M, McDermott LL, Rouhana N, Schmidt M, Seymour MW, Sullivan T. Nurses' body size and public confidence in ability to provide health education. J Nurs Scholarsh 2008; 40(4): 349-354.

[5] Mak YW, Kao AHF, Tam LWY, Tse VWC, Tse DTH, Leung DYP. Health-promoting lifestyle and quality of life among Chinese nursing students. Prim Health Care Res Dev 2018; 19(6): 629636.

[6] Atlam DH, Aldemir E, Ender Altintoprak A. Prevalence of risky behaviors and relationship of risky behaviors with substance use among university students. Dusunen Adam 2017; 30(4): 287-298.

[7] Coskun S, Bebis H. Effects of health promotion courses on development of healthy lifestyle behaviours and e-health literacy in nursing. Gulhane Med J 2019; 61: 52-58.

[8] Karaca T, Aslan S. Determination of health status perceptions and healthy lifestyle behaviors of nursing students. ACU Health Sci J 2019; 10(4): 734-739.

[9] World Health Organization. Four-year Integrated nursing and midwifery competency-based curriculum for the African region. Geneva:2016

[10] Intarakamhang U, Malarat A. The effects of behavioral modification based on Client Center Program to health behaviors among obese university students. Glob J Health Sci 2014; 6: 1

[11] Heeren GA, Jemmot JB, Marange CS, Gwaze AR, Batidzirai JM, Ngwane $Z$ et al. Health-promotion intervention increases selfreported physical activity in Sub-Saharan African University students: a randomized controlled pilot study. Behav Med 2018; 44: 297-305.

[12] Melnyk B, Kelly S, Jacobson D, Arcoleo K, Shaibi G. Improving physical activity, mental health outcomes, and academic retention in college students with Freshman 5 to Thrive: COPE/Healthy Lifestyles. J Am Assoc Nurse Pract 2014; 26(6): 314-322.

[13] Lee KS, Lee JK, Yeun YR. Effects of a 10-day intensive health promotion program combining diet and physical activity on body composition, physical fitness, and blood factors of young adults: a randomized pilot study. Med Sci Monit 2017; (23): 1759-1767.

[14] Matvienko O, Lewis DS, Schafer E. A college nutrition science course as an intervention to prevent weight gain in female college freshmen. J Nutr Educ 2001; 33: 95-101.

[15] Brown DM, Bray SR, Beatty KR, Kwan MY. Healthy active living: a residence community-based intervention to increase physical activity and healthy eating during the transition to first-year university. JACH 2014; 62: 234-242.

[16] Esin N. Adaptation of the health promoting lifestyle profile to Turkish. Nurs Bull 1999; 12(45): 87-95.

[17] Kalayci S. SPSS applied multivariate statistical techniques. Ankara: Asil Publishing 2009.

[18] Hsiao YC, Chen MY, Gau YM, Hung LL, Chang SH, Tsai HM. Short-term effects of a health promotion course for Taiwanese nursing students. Public Health Nurs 2005; 22(1): 74-81.
[19] Mc Sharry P, Timmins F. An evaluation of the effectiveness of a dedicated health and well being course on nursing students' health. Nurse Educ Today 2016; 44:26-32.

[20] Yeh L, Chen CH, Wang CJ, Wen MJ, Fetzer SJ. A preliminary study of a healthy-lifestyle-promoting program for nursing students in Taiwan. J Nurs Educ 2005;44(12): 563-565.

[21] Erenoglu R, Can R, Sekerci YG. The effect of the health promotion program for young people on health behaviors, health perception, and self-efficacy levels: a randomized controlled trial. J Caring Sci 2019;12(2):1203.

[22] Gill M, Chan-Golston AM, Rice LN, Roth SE, Crespi CM, Cole BL, Koniak-Griffin D, Prelip ML. Correlates of social support and its association with physical activity among young adolescents. Health Educ Behav 2018; 45(2): 207-216.

[23] Wang J, Mann F, Lloyd-Evans B et al. Associations between loneliness and perceived social support and outcomes of mental health problems: a systematic review. BMC Psychiatry 2018; 18: 156.

[24] Yalcin I. Relationships Between Well-Being and Social Support: A Meta-Analysis of studies conducted in Turkey. Turk Psychiatry J 2015; 26(1): 21-32.

[25] Liu W, Mei J, Tian L, Huebner ES. Age and gender differences in the relation between school-related social support and subjective well-being in school among students. Soc Indic Res 2016; 125(3): 1065-1083.

[26] Göger S, Cingil D, Kılavuz Ören G. Determining the healthy life style behaviors and the levels of physical activity of women who are registered to a sports center. Journal of Health and Society 2019; 29 (1): 89-97.

[27] Yılmazel G, Duman BN. Healthy lifestyle behaviors and preventive health applied to women ages 18-64: a sample from the Corum province. TAF Prev Med Bull 2016; 15(2): 92-97.

[28] Kocaman F, Telatar B. Evaluation of health related quality of life, healthy lifestyle behaviors and weight loss interventions according to body mass index in adults. TJFMPC 2020; 14 (4): 497-504.

[29] Diener E, Ryan K. Subjective well-being: a general overview. South African Journal of Psychology. 2009;39(4):391-406.

[30] Kaczynski AT, Manske SR, Mannell RC, Grewal K. Smoking and physical activity: A systematic review. American Journal of Health Behavior 2008; 32(1): 93-110.

[31] Gimeno-Santos E, Frei A, Steurer-Stey C, de Batlle J, Rabinovich RA, Raste $Y$ et al. Determinants and outcomes of physical activity in patients with COPD: A systematic review. Thorax 2014; 69(8): 731-739.

[32] Nystad W, Samuelsen So, Nafstad P, Langhammer A. Association between level of physical activity and lung function among Norwegian men and women: The HUNT study. IJTLD 2006; 10(12): 1399-1405.

[33] Paulo R, Petrica J, Martins J. Physical activity and respiratory function: Corporal composition and spirometric values analysis. Acta Medica Portuguesa 2013; 26(3): 258-264.

[34] World Health Organization. Global action plan on physical activity 2018-2030: More active people for a healthier world. Geneva: 2018. 